\title{
HIV-helminth coinfection: is deworming necessary?
}

\section{Zvi Bentwich*}

\author{
Address: Center for Infectious Diseases and AIDS, Ben Gurion University Faculty of Health Sciences, Beer Sheba, Israel \\ Email: Zvi Bentwich* - bzvi@bgu.ac.il \\ * Corresponding author
}

from 2006 International Meeting of The Institute of Human Virology

Baltimore, USA. 17-2I November, 2006

Published: 2I December 2006

Retrovirology 2006, 3(Suppl I):S79 doi:I0.I 186/1742-4690-3-SI-S79

(c) 2006 Bentwich; licensee BioMed Central Ltd.

\section{Background}

We have previously suggested that helminth infections play a major role in the pathogenesis of HIV-1 infection in Africa and other developing countries, due to their profound effects on the host immune system, which make those infected more susceptible to HIV-1 infection and less able to cope with it. We present here our own studies and review all studies in humans and primates.

\section{Methods}

Several population groups including Ethiopian immigrants in Israel (ETI), Ethiopians in Ethiopia (ET) and other African populations, as well as primates, infected and non-infected by both helminths and HIV or SIV, were studied sequentially, clinically and immunologically, before and after helminth eradication.

\section{Results}

1) Helminthic infections induce a state of chronic immune activation and anergy. 2) Eradication of helminths by itself, (independent of changes in nutrition and environment), is followed by gradual return of the immune profile to normal values. 3) PBMC of ETI are more susceptible to HIV infection 4)) Deworming can be associated with significant decrease of VL in helminth and HIV coinfected individuals.

\section{Conclusion}

Cumulative immunological and epidemiological evidence is in favor of deworming as a preventive and possible therapeutic measure vis-a-vis HIV infection. It should be at least tested on a wider and larger scale because of its immense potential impact on the still raging AIDS epidemic in developing countries. 